EMBRYARIDDLE
Aeronautical University

SCHOLARLY COMMONS
International Journal of Aviation, Aeronautics, and Aerospace

\title{
Methodology for Convergence of the Training Program with the Professional Activities of Aviation Specialists
}

\section{Zair Ziyaevich Shamsiev}

Tashkent state transport university, shamzz@rambler.ru

Follow this and additional works at: https://commons.erau.edu/ijaaa

Part of the Educational Methods Commons, and the Multi-Vehicle Systems and Air Traffic Control Commons

\section{Scholarly Commons Citation}

Shamsiev, Z. Z. (2021). Methodology for Convergence of the Training Program with the Professional Activities of Aviation Specialists. International Journal of Aviation, Aeronautics, and Aerospace, 8(1). https://doi.org/10.15394/ijaaa.2021.1550

This Special Purpose Document is brought to you for free and open access by the Journals at Scholarly Commons. It has been accepted for inclusion in International Journal of Aviation, Aeronautics, and Aerospace by an authorized administrator of Scholarly Commons. For more information, please contact commons@erau.edu. 
The educational process is a priority part of human activity, on the perfection of which the level of the social and economic environment of society depends. In this regard, it should be in the field of special attention.

The educational system in the Republic of Uzbekistan (hereinafter Uzbekistan) is based on the state educational standard, developed separately for each area of undergraduate education and each specialty of the magistracy. The standard contains norms and requirements for the level of knowledge of the student. Failure to comply with the norms and requirements gives reason for the supervising organization to consider the process of training personnel in an educational institution as inconsistent with the standard. If the violation of the norms and requirements of the standard is serious, then the controlling organization makes a decision to close the direction of education for bachelor's or master's degree. If it is insignificant, then decisions are made to eliminate the degree.

The level of training and the correspondence of the accumulated volume of theoretical and practical knowledge to the requirements of the consumer of personnel are determined by the programs of educational disciplines. If the composition and content of the programs fit into the framework of the requirements, then with the correct and full-fledged conduct of the educational process, the graduate of the educational institution will not have any special problems with finding a job. However, the process of preparing and approving curricula is characterized by the presence of hidden negative factors that do not attract special attention. This is due to the fact that they have acquired a traditional form and are considered the norm.

The current method of curriculum design is entirely related to the teacher's experience. The draft curriculum is usually developed by two leading teachers. In general, the process of developing, agreeing, and using the program can be represented by the diagram shown in Figure 1. The figure shows that each program for a particular academic subject goes a long way to get the right to life, and this path consists of 10 technological stages, at each of which objective and subjective errors are made. In general, the accumulation of errors without specifying their type, their composition can be formally represented by the expression

$$
\mathrm{E}=\sum_{i=1}^{n} \mathrm{e}_{\mathrm{i}}(n=\overline{1,10}),
$$

where: E- total error accumulated from errors made at certain stages of the program development and approval process; $\mathrm{e}_{\mathrm{i}}$ - an error made at certain stages of the program development and approval process. 


\section{Figure 1}

Technological Stages of Development, Coordination, and Use of the Program of the Academic Subject

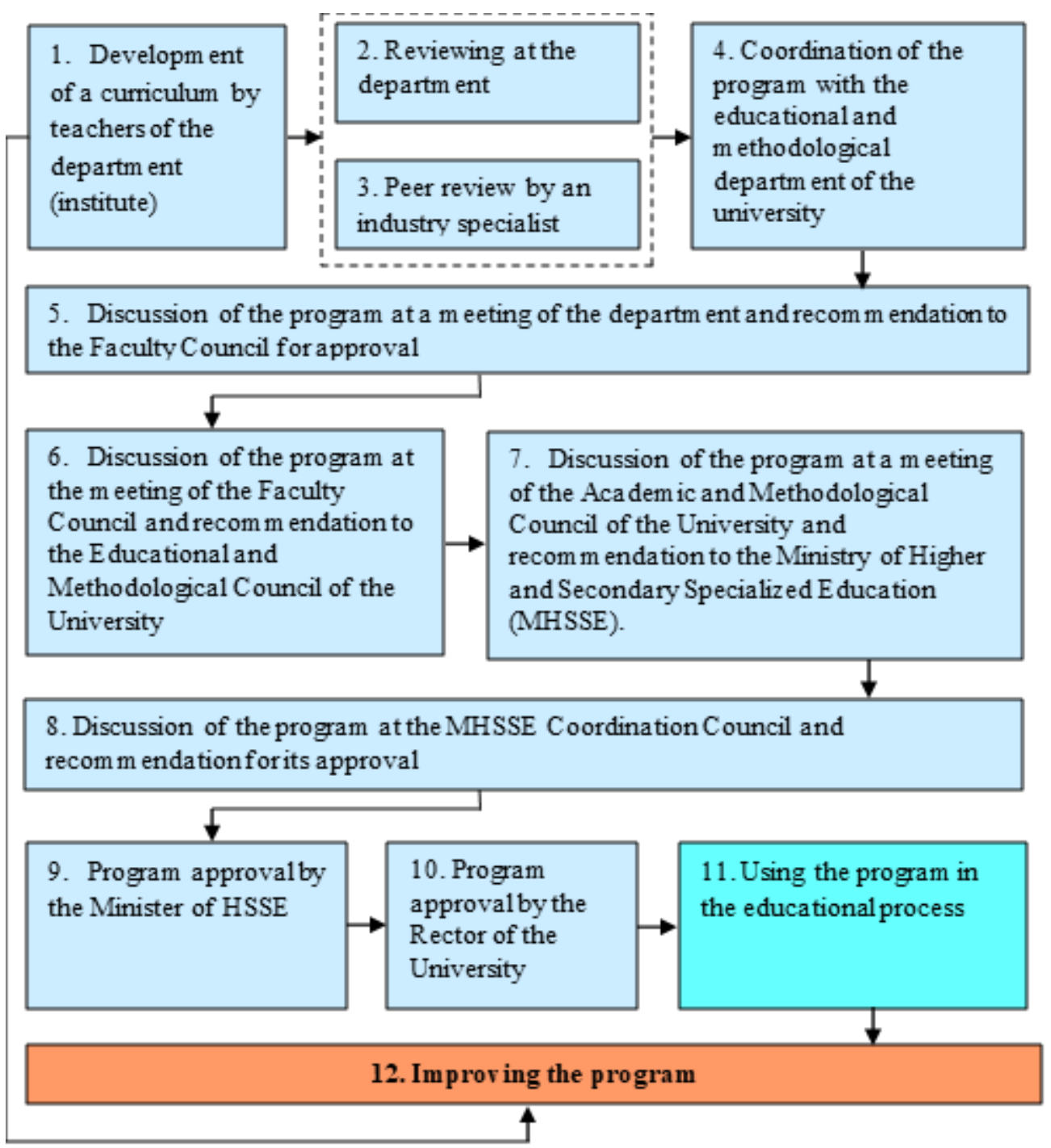

The analysis of this process showed that professional activity towards convergence of the composition and content of the program is observed only at stages 1 and 3 . Then the program goes through a bureaucratic path, since the department (institute) trusts the teacher and reviewers, the faculty trusts the department, the university trusts the faculty, and the ministry trusts the university. At the same time, the faculty, university and ministry do not have the resources to carry out additional expertise. At stages 4-10, attention is paid only to the structure and form of the program, and the content is left without attention. At the level of the ministry, the process becomes one hundred percent formality, since the number of programs coming from all universities in 
Uzbekistan for consideration and approval is several thousand pieces. Stage 12 begins after the completion of the educational process and does not fundamentally change the content of the program, with the exception of some minor changes that are made for the students of the next set. It is obvious that this technology is the fruit of a centralized system of organization, management, and regulation of the educational process.

The established technology of developing and approving the curriculum and moving it toward approval generates human errors that lead to a weak connection between the educational process and the workplace of the future specialist. Due to this, a specialist who has received an education, even while meeting the requirements of the state educational standard, is not quite close with his theoretical and practical knowledge to the future workplace. Ideally, after completing his studies, he should be able to be accepted into the robot and, without adaptive measures, start performing his official duties. This is almost never observed. Within this framework, it should be emphasized that the insufficient adequacy of the graduate's knowledge to the requirements of the workplace can in the future lead to very undesirable events in the field of flight safety, which in no way can be allowed. Flight safety for civil aviation is a priority.

The undesirable reality described above should be eliminated by research, the results of which will make it possible to exclude from the educational process any non-scientifically grounded or volitional methods of preparing regulatory and methodological documents. To determine the place and role of this study, it is advisable to review existing scientific works devoted to improving the quality of the educational process by bringing the educational process closer to the graduate's workplace.

A large number of scientific and methodological works are devoted to the study of the educational process and its components, including methods of organizing and conducting theoretical and practical classes. This article analyzes the publications closest to the topic.

The article by McGunagle et al. (2020) is devoted to the problem associated with the implementation of the target function of an educational institution - it is preparing graduates for work. It explores the skills of graduates in science, technology, engineering, and mathematics (STEM), nominated by employers, and the elimination of existing gaps that negatively affect success in employment. The authors examined 16 job placement skills and their application to STEM students. Their analysis was based on a survey of 250 managers from 5 manufacturing industries (aerospace and defense, automotive, consumer goods, electronics, and manufacturing) in the United States. Based on the average of the survey data, the conclusion about the importance of all 16 skills in employment is confirmed. This reveals the 5 most important skills team player, self-motivation, verbal communication, problem solving and proactivity. The main motive of the study is to narrow the gap between the competencies of graduates and the practical needs of the workplace. The research findings are a call to stakeholders of STEM education institutions, both 
internal and external, to review current curricula and programs, and to collaborate to narrow the gap between graduate competencies and the practical needs of the workplace. The article notes the need for this work by specialists from the industry and an educational institution. The value of the research is expressed in the universality and globality of the conclusions.

From the standpoint of satisfying the skills of future aviation dispatchers at the workplace, an article by Coyne et al. (2017) is of interest, which analyzes students' perception of the use of simulators with high fidelity. The results suggest that researchers and administrators should consider the use of modeling as an integral part of teaching methods. Students prefer modeling when integrated with traditional teaching methods. From the student's point of view, there are more benefits to using air traffic control simulators. From this study, a very important conclusion is made that when drawing up training programs in the context of universities mastering new teaching technologies using modeling, it is necessary to take into account the opinions of students. Thus, students, as an interested party, act as an opponent - they must be aware of what and how they are being taught.

The publication by Watkins et al. (2016) examined the work of HR and hiring managers, as well as their actions to select people for positions for a specific job. Attention is focused on the systematization of knowledge, skills, and abilities (KSA), according to which the professional and personal qualities of job candidates are assessed. In this context, attention is paid to the fact that KSA are composed of elements that include education, certification, and experience (ECE), therefore the question is raised about identifying the relationship of education, certification and experience with KSA. It is concluded that the wrong set of KSAs can lead to high costs for the organization. The study is based on the triangulation method, which improves the accuracy of the resulting data. The collection of statistics was carried out through a survey of 404 professionals in the aviation industry. The study confirms the previously advanced theory that education, certification, and experience are the building blocks of knowledge, skills and abilities. As a key finding from the study, the authors suggest that more research is needed to understand the specific relationship between ECE and KSA. It is argued that industry models should be built to help HR professionals improve recruitment, work planning, training, and performance management. Finally, from a practical point of view, educators are encouraged to use more ways of hands-on and experiential learning. Analysis of this publication shows that it is extremely important for an educational institution and personnel consumers to take joint actions to bridge the gap between the educational process and the graduate's workplace. Thus, the whole point of the study comes down to modernizing the curriculum, based on the requirements of the workplace.

From the point of view of increasing the effectiveness of education, taking into account the degree of reality of virtual learning using various simulation tools, the publication by Fussell et al. (2020) deserves attention. In it, the authors emphasize the progressiveness of this type of direction in 
achieving a solid mastery of the skills of the aviation profession. However, they note the lack of knowledge of their features, which does not give them a reason to draw any definitive conclusions about their comprehensive benefits without proper research. Therefore, the authors of this publication in the pilot study set the goal of identifying, validating and confirming the influencing factors related to the use of virtual tools in aviation training, as well as in flight training in general. The research is based on a survey of students using a questionnaire developed using Google Forms. The results of the pilot study made it possible to identify the factors and elements of virtual funds that need to be revised before mass distribution. These results provide a preliminary idea of how students perceive the use of virtual reality and the factors that can negatively influence the adoption and ultimately the use of this type of technology for training aviation professionals.

The results of the study aof Coyne's 2014 study are also important. This publication provides an overview of current tasks in the field of air traffic controller training. The study was commissioned by the FAA to review the procedures used in training air traffic controllers. The systemic conclusion is the establishment of the possibility of implementing the initial level of education in universities, which gave reason to bypass this level at the FAA Academy. The end result was a CTI program that covered the basics of air traffic control and expanded to 36 universities. A feature of the study is the creation of evidence for the opportunity to train entry-level specialists on the basis of universities. The results of the study concluded that the CTI program closely approximated the actual workplace of an air traffic controller, which in turn simplified the hiring process.

From the standpoint of the effective use of the academic time budget, which is largely determined by the composition and content of the curriculum, the publication by Kazak et al. (2017) is of interest. This publication discusses the issues of improving the efficiency of educational process management for aviation specialists by optimizing the time structure. It is concluded that the process of perception and memorization of information is influenced by the allotted time, structure and sequence of training, the formation of information links between blocks of educational information, the frequency of using concepts and the speed of information transfer. The process of training aviation specialists and its structuring are proposed, the distribution of operating time is taken as a basis. The results of this study can be used as an argument about the appropriateness of the initially correct construction of the training program. With even a brilliant academic time management mechanism, learning outcomes can remain outside the workplace.

Oleg et al.'s 2019 work is devoted to the study of the influence of students' personal qualities on the learning process. In it, based on the methodology of statistical analysis of student survey data, conclusions are formulated about the need to take into account the personal qualities of students for the correct choice of teaching methods. The change in their attitude depending on the year of study is taken into account. The author comes to the 
conclusion that the use of the method of statistical analysis of student survey data will allow choosing the correct teaching methodology, taking into account their personal qualities. At the end of the study, the fact of establishing the professionally important qualities of aviation technical personnel, as well as the identified conditions and features of their formation, development and assessment in the learning process, is confirmed.

Faulconer et al.'s 2020 research addresses issues related to nextgeneration science standards and other educational reforms that should support and develop the building of deep links between STEM disciplines. It is noted that integrated STEM is the highest priority approach for the targeted implementation of disparate disciplines. However, it is noted that the integration of non-STEM disciplines is not well understood and is usually limited to art integration (STEAM). Humanistic STEAM combines STEM learning with an interest and concern for human affairs, welfare, values, or culture. Based on the state of the art in the field of study, the study examines the introduction of the humanities into an online course in the discipline of chemistry. This procedure was performed in order to establish the significance for the student of the existence of a connection between the course content and interdisciplinary perspectives. To establish this fact, the results of a survey of students are analyzed regarding the presence of a clear connection between the course and STEM disciplines, between science and non-science, between science and the real world, as well as an expanded perspective of the connection of science with other courses in their degree programs. In conclusion, it is concluded that it is necessary to develop a pilot study to obtain fundamental results in this area. The significance of this work is primarily characterized by the statement of the fact that it is necessary to develop training programs.

The analysis of the educational document of one of the state universities in Russia showed that the approaches proposed in them for converging the curriculum to the requirements of the labor market are of a general recommendation nature, there is no clear technology for their implementation. As an example, we studied the methodological material (Afanasyeva et al., 2007), developed by a team of teachers from Moscow State University to implement the requirements of the Federal State Educational Standards (FSES) of vocational education (VE) of the Russian Federation. In the section of the document concerning the design of the content of subject educational programs, it is written: "In the paradigm of the Federal State Educational Standard (FSES), the main document developed by the university and introduced by it to the educational services market is the "Basic educational program of higher professional education of a certain level in a specific area of training/specialty." At the same time, each FSES higher professional education provides for the addition and concretization of the qualification and competence portrait of the graduate, taking into account the real labor market, on which the work of the university is focused. "Each such program must be signed by representatives of employers in the region concerned" (Afanasyeva et al., 2007, p 15). It is not difficult to understand that the formation of the composition of academic 
disciplines and their content, which should be reflected in the curriculum, are ultimately determined by employers. However, it is not clear from the text how employers will fulfill the powers delegated to them, it is not clear on what predeveloped and approved method they will solve such an important task.

In the context of the publication (Afanasyeva et al., 2007), it is advisable to consider the collection of abstracts, reports and articles of the methodological conference entitled "Development of Educational Programs in the Context of Increasing the Competitiveness of Economic Education" (Grudzinsky, 2017). The conference was held by the National Nizhny Novgorod State University, named after N. I. Lobachevsky, on February 6-8, 2017. From the title of the conference and the content of its collection it is clear that it is entirely devoted to the problems of educational programs. This collection contains an article (page 5), which describes the use of marketing tools to assess the quality of educational services. The research materials are based on data from a survey of graduate students on the quality of their education. The assessment of education was carried out on a 5-point scale for three groups of factors: "The level of organization of educational activities," "Learning conditions," and "Teaching quality." The main results are processed survey data, which characterize the weight share of factors characterizing the quality of education. The conclusions are of a general recommendation nature. Specific targeted proposals for improving the curriculum are poorly expressed.

For a strong argumentation of the importance of choosing a method for drafting curricula, it is appropriate to refer to the publication (Stabback, 2016). The publication contains requirements for educational programs, formulated by UNESCO in the form of questions:

- Are there clear aims for the curriculum?

- Is the curriculum up to date?

- Is it relevant to students' current and future lives, experiences, environments and aspirations?

- Does it create a socially and economically prosperous future while respecting the country's past - its cultural history and traditions?

- Is the curriculum equitable and inclusive? (i.e., does it take into account the diversity of learners and the different learner needs; does it cater for marginalized groups; does it avoid biases)

- Is the curriculum learner-centered and learner-friendly? (i.e., does it take learner needs into account; does it avoid biases and discrimination; is it well sequenced with regard to the learners' age; does it contribute to personal development and life skills; does it make sense - is it meaningful for learners; does it avoid overloading learners)

- Is the curriculum open and flexible, so that it can address new challenges and opportunities by integrating new/emerging issues?

- Is the curriculum coherent and consistent across different education stages/grades/streams and learning areas/subjects? 
Based on the analysis of publications, it can be concluded that all these studies provide for one goal - this is the maximum approximation of the knowledge of graduates to the requirements of their future workplace, - this is the care and protection of the student's rights to receive viable knowledge. In this context, it should be noted the place and role of ICAO in the systematic training of aviation specialists. ICAO has developed and issued a special document (ICAO, 2011), which provides basic recommendations for the organization, provision and conduct of the educational process. For the effective implementation of the recommendations of this important international document, first of all, it is necessary to develop, as it was said above, the correct curriculum, which is close to the composition of the functions of a specialist's workplace.

\section{Materials and Methods}

This work sees its goal in the development of methodological recommendations for the maximum convergence of the composition and maintenance of training programs to the conditions and requirements of aviation enterprises engaged in air transportation. The main tasks are to ensure the maximum approximation of the composition and content of the curriculum for training aviation specialists with higher education are:

- analysis of the civil aviation regulatory documents of Uzbekistan governing the certification procedures for aviation personnel;

- identification of features and requirements for the composition and content of theoretical and practical knowledge of aviation personnel;

- formation of proposals for the approximation of the composition and content of the curriculum to professional responsibilities and workplace requirements.

For statistical analysis of data on the research topic, a regulatory document of the civil aviation of Uzbekistan (AP RUz-61, 2020) was taken, which was developed and adopted for implementation which was developed and adopted for execution within the framework of the Air Code of Uzbekistan (Vozdushnyj Kodeks Respubliki Uzbekistan, 1993; AP RUz-71, 2011; AP RUz-91, 2007; AP RUz-96, 2013, etc.), Appendix 1 of the Chicago Convention (Doc 7300/9, ICAO, 2006) and ICAO recommendations (Doc 7192-AN/857, ICAO, 2011). If necessary, additions and clarifications are made to the content of the document (AP RUz-61, 2004). In particular, the latest clarification was introduced in September 2018. The document contains a section "The list of questions used in the presentation of requirements for aviation personnel when obtaining a certificate, extending the validity of the certificate, when assigning a class, qualifications, class confirmation, qualifications." The section contains the requirements for the knowledge and skills of pilots, navigators, flight engineers, flight mechanics, flight radio operators, flight operators, flight attendants, dispatchers, flight operations officers, radio bureau signalmen, amateur pilots, balloon pilots, ultralight aircraft pilots, and glider pilots, engineering the composition and requirements for making the mark of the flight 
crew instructor. Each of these types of aviation personnel is provided with a list of areas of expertise and associated questions.

Comparative analysis of the composition of knowledge areas and topics on which certification issues are formulated with the training program for each type of aviation personnel is associated with the presentation of a large amount of material. For this reason, this article highlights the research results using the example of air traffic control certification.

To certify the theoretical knowledge of dispatchers in the document (AP RUz-61, 2004), there are areas of knowledge with a certain number of topics and requirements or conditions for skills and abilities for each of them:

1. Air law.

2. Flight rules and basics of air navigation.

3. Air traffic accidents.

4. Air traffic services.

5. Guidelines for radiotelephone communications in civil aviation.

6. Aviation meteorology.

7. Radio-technical means of air traffic control.

8. Foreign language.

9. Human capabilities and limitations in relation to air traffic control.

10. Basics of aerodynamics, aircraft performance characteristics.

11. The dispatcher must have experience and skill.

12. Additional requirements for knowledge before obtaining the relevant qualification mark:

13. Additional requirements for experience (internship) before obtaining the appropriate qualification mark.

According to the above list of knowledge areas in compliance with their serial number, a diagram (see Figure 2) of the distribution of the number of topics, requirements and conditions is built.

\section{Figure 2}

Distribution of the Number of Topics by Areas of Knowledge for Certification of Knowledge of Air Traffic Controllers and The Issuance of a Certificate in Accordance with the Document AP RUz-61 (2004) 


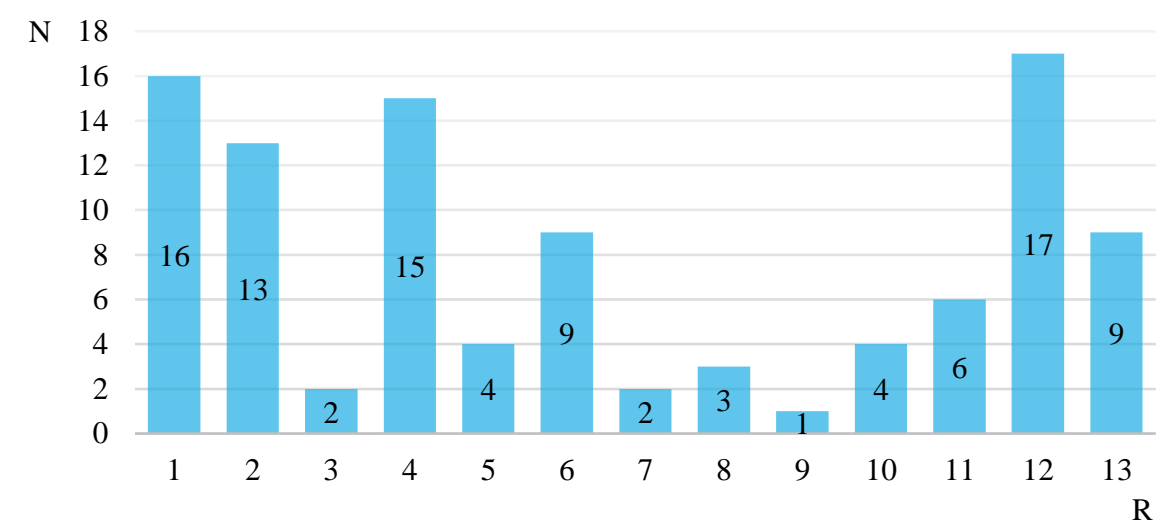

Note. $\mathrm{N}$ - the number of topics (questions); $\mathrm{R}$ is the ordinal number of the area of expertise

The diagram shows that by the number of topics, requirements, and conditions for which the certification of dispatchers is carried out, the areas of knowledge vary greatly, but this is only the quantitative side of the issue. If we consider the content side, then knowledge areas with a small number of topics, requirements and conditions can have a larger information volume. Due to the fact that the purpose of the study does not pursue the consideration of issues in this aspect, but only pays attention to the methodological aspects, the solution of the problem of a qualitative assessment is not provided.

As a follow-up to the document AP RUz-61 (2004), the State Unitary Enterprise "Center" Uzaeronavigatsiya" under the Ministry of Transport of Uzbekistan has developed its own internal document for the certification of dispatchers. The document consists of 1103 questions from the following areas of knowledge:

1. Air Code of Uzbekistan.

2. Rules for the use of the airspace of Uzbekistan.

3. Flight rules and basics of air navigation.

4. Manual on air traffic management of the Uzaeronavigatsia Center.

5. Air traffic services in civil aviation.

6. Radiotelephone communication in civil aviation.

7. Rules for the investigation of aviation accidents and incidents with civil aviation in Uzbekistan.

8. Radio-technical means of air traffic control.

9. Aviation meteorology.

10. Aviation accidents and incidents.

According to the above list of knowledge areas, observing their numbering in the above list, a diagram (see Figure 3) of the distribution of the number of questions by areas of knowledge is built, which illustrates a significant difference in the number of questions. 
Shamsiev: M ethodology for convergence of the training program with the professional activities of aviation specialists 
Figure 3

Distribution of the Number of Topics by Areas of Knowledge, Given in the Document of the Center "Uzaeronavigatsia" for Certification of Knowledge of Air Traffic Controllers

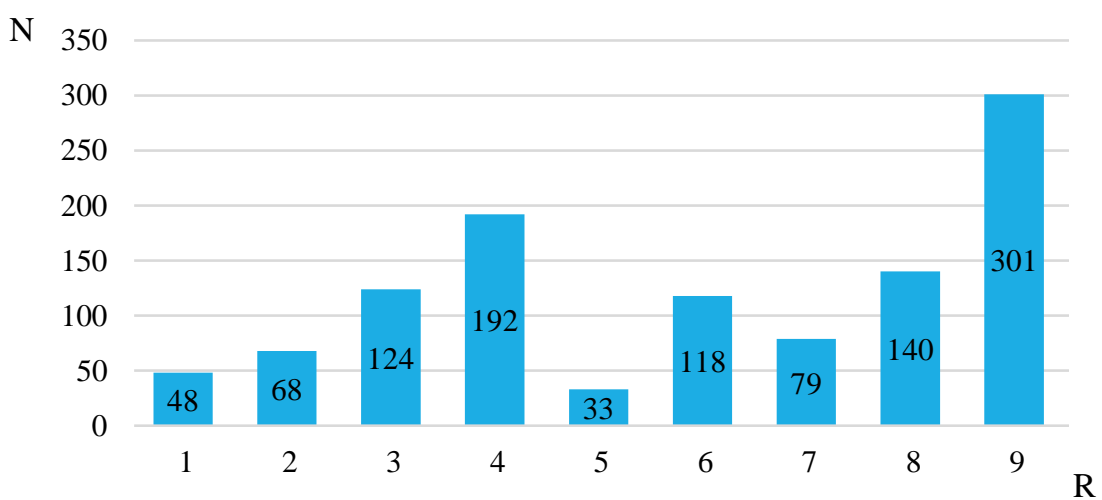

Note. $\mathrm{N}$ - the number of topics (questions); $\mathrm{R}$ is the ordinal number of the area of expertise.

Thus, Figures 1 and 2 clearly show the composition of knowledge that an air traffic controller should have. In shaping the curriculum, the developer should be based on such statistical analysis. Another important aspect of this method is the establishment of the number of hours for academic disciplines. The method under consideration can serve as the basis for the correct choice of the principle of allocating academic hours between disciplines. Of course, it is necessary to take into account the complexity and volume of the training material.

The next task was to analyze the compliance of the requirements and conditions given in the document (AP RUz-61, 2004) with the current training program. A detailed analysis was carried out only for those positions that are more related to the educational process of the university. The work performed in the context of this task, in the areas of knowledge listed above, showed the following:

1. Field of knowledge "Air law" is studied within the academic discipline "Transport legislation." This academic subject is included only in the curriculum of some professional disciplines, it is not included in the curricula of individual disciplines, although the study of regulatory documents relating to this area of knowledge is very important. Based on the analysis data, it can be concluded that there is no clear link between the curriculum and this area of knowledge. Along with this, it should be noted that the concept of "Transport legislation" is much broader in meaning than the concept of "Air law." According to this name, the student is presented with information in a larger volume, which includes knowledge that does not relate to his future profession of an air traffic controller. 
2. Field of knowledge "Flight rules and basics of air navigation," is studied separately within the framework of two separate academic disciplines:

- "Organization and maintenance of air traffic."

- "Air navigation and flight navigation support".

Such an approach of divided learning complicates the perception of the material separately, and during certification it creates difficulties mentally to generalize and reproduce information within the framework of one name of the field of knowledge. It can be concluded that in this part there is no common position between the employer and the university.

3. Field of knowledge "Aviation accidents related to air traffic services" are studied within the framework of a separate academic discipline "Flight safety and human factor". In this position, there is a discrepancy between the name of the field of knowledge and the academic discipline, which makes it difficult to assess the proximity of the material of the academic discipline with the name of the field of knowledge.

4. The area of knowledge "Air Traffic Services" is studied in the framework of the discipline "Organization and maintenance of air traffic." This fact deserves approval, but leads to the question: - To what extent in the academic discipline is attention paid separately to "air traffic management" and "air traffic services"?

5. The area of knowledge "Guidelines for radiotelephone communication in civil aviation" is studied within the framework of a separate academic discipline "Rules of phraseology in radio exchange." In this case, there is a discrepancy between the names, which leads to the question: - How is radiotelephone communication and the rules of phraseology in radio exchange combined?

6. Area of expertise "Aeronautical Meteorology." This area of knowledge is studied in the framework of the discipline "Aeronautical Meteorology." The name of the area of knowledge required by the civil aviation regulatory document coincides with the name of the academic discipline. This fact is positive. However, there are certain omissions in the composition of topics and content.

7. Field of knowledge "Radio engineering means of air traffic control." It is studied within the framework of a separate academic discipline "Radio engineering support of flights and landings." The name of the discipline does not cover the processes of managing maneuvers on the airfield area. Based on this, it is advisable to change the existing name of the academic discipline to "Radio-technical means of air traffic control."

8. Field of knowledge "Foreign language." It is studied within the framework of a separate academic discipline "Professional English." This fact is positive. However, the recommendations of the document (Cir 323 AN/185 ICAO, 2009) on the coverage of the six aspects of language proficiency on the ICAO qualification scale and the descriptors of language skills in the training program are not clearly presented. At the same time, the assessment of 
knowledge on the aspects of ownership is not carried out separately, which reduces the level of preparedness.

9. Area of knowledge "Human capabilities and limitations in relation to ATC" (human factor influence). It is studied within the framework of the academic discipline "Flight Safety and the human factor." However, it is not clear how the materials of the discipline are strictly related to the dispatcher's workplace. Familiarization with the curriculum of the discipline showed that the materials are of a general nature, they are little related to the professional activities of the dispatcher.

10. Field of knowledge "Fundamentals of aerodynamics, flight characteristics of aircraft." It is studied in the framework of a separate academic discipline "Aerodynamics and design of aircraft". Familiarization with the program of this discipline showed little information content of materials in the field of on-board systems of modern civil aviation aircraft, which led to a significant discrepancy from the list and content of topics in this field of knowledge given in the civil aviation certification document.

11. Area of expertise "The dispatcher must have experience and skill in the following areas." For this area of expertise, the document provides the following requirements:

a) be able to control air traffic in accordance with the technology of work;

b) master the rules and phraseology of radio traffic in air traffic control;

c) act correctly and in a timely manner in various air and meteorological situations; operation;

d) competently use ATC radio and communication facilities during

e) clearly interact with adjacent control points, services and bodies providing and controlling aircraft flights;

f) promptly inform the relevant assistance services for aircraft in distress at the aerodrome and (or) in the area of responsibility.

Let us analyze the above requirements using the example of position "a," since the analysis of the other requirements below is of the same nature.

To fulfill the requirement "a" in the educational process, the training program "Technology of air traffic controller work" is provided. Requirement "a" in the program should be implemented based on the ICAO recommendation set out in the document (Doc 7192-AN/857, ICAO, 2011). For example, in the member states of the European Union, this requirement is fulfilled by complying with the document (Publications Office of the EU, 2015). According to this document, the training of an air traffic controller in Europe consists of mastering the basic course and obtaining the appropriate ratings. The term "rating" refers to the mastery of operations at the respective workplace, namely:

- ADI TWR + RAD rating. (Aerodrome Control Instrument with Tower \& Radar Endorsement) control of movement in the airfield area by radar services; 
- APP rating. (Approach Control Procedural) procedural control in the approach area;

- APS + RAD rating. (Approach Control Surveillance with Radar Endorsement) air traffic control in the approach area with radar services;

- ACS + RAD rating. (Area Control Surveillance with Radar Endorsement) air traffic control in the control area with radar services;

- ASC + RAD rating. (Automated system of control with Radar Endorsement).

The stated requirement is also reflected in the document (AP RUz-61, 2004), however, such structuring is not observed in the program "Technolology of the Air Traffic Controller's Work." The state of the issue gives the right to conclude that there is a large gap between the curriculum and the requirements of the workplace in this area of knowledge. The knowledge of the graduate is little adapted to the future workplace.

The above results of statistical analysis can be expanded, but there is no great need for this, because within the framework of each requirement, it is possible to find the existence of a sufficiently large gap between the curriculum and the requirements of personnel consumers. The gap is observed both in the composition of the fields of knowledge and in their content.

\section{Main Result}

It has been established that with the traditional method of developing curricula, a wide range of errors is allowed and the requirements of personnel consumers to the composition and content of a graduate's knowledge are not sufficiently taken into account. Statistical analysis made it possible to establish the following main inconsistent positions between the requirements and conditions of the employer and the training programs for aviation dispatchers:

a) there are discrepancies between the names of the areas of knowledge for which the certification of air traffic controllers by the employer is performed, and the training programs;

b) the curriculum lacks specific topics that are included in the area of knowledge;

c) lack of a clear link between the training process and the workplace, which is especially observed in the formation of theoretical knowledge and practical skills and abilities within the framework of the organization of structural air traffic control bodies, organized taking into account the environment of aircraft movement;

d) there is no justification for setting academic time in academic disciplines, etc.

\section{Conclusion}

Based on the study, the following main recommendations were formulated to determine the adequacy of training programs for air traffic controllers in Uzbekistan to the requirements of personnel consumers:

a) the proposed method will increase the level of adequacy of training programs to the requirements of personnel consumers, and also reduce the share 
of the human factor in planning the composition and content of the graduate's knowledge, which allows avoiding subjective errors;

b) the proposed method can be used not only for the formation of regulatory and methodological materials in the aviation direction of education, but also for others;

c) the proposed method for drawing up curricula has greater objectivity, since there are no subjective errors in it, along with this, it allows to significantly reduce the time and material costs for adapting a young specialist to real working conditions and to carry out his admission to work as soon as possible. 


\section{References}

Afanasyeva, T. P., Karavaeva, E. V., Kanukoeva, A. S., Lazarev, V. S., Nemova, T. V. (2007). Methodological recommendations for the development and implementation, based on the activity-competence approach, of educational programs of HPE, focused on the third generation. Publishing house of Moscow State University.

AP RUz-61. (2020). Vidacha svidetelstv i klassifikatsiya aviatsionnogo personala grajdanskoy aviatsii Respubliki Uzbekistan. https://www.lex.uz/acts/723371

AP RUz-71. (2011). Obslujivanie vozdushnogo dvijeniya v grajdanskoy aviatsii. https://lex.uz/acts/1743708

AP RUz-91. (2007). Pravila poletov grajdanskoy i eksperimentalbnoy aviatsii $v$ vozdushnom prostranstve Respubliki Uzbekistan. https://www.lex.uz/docs/1261836

AP RUz-96. (2013). Radiotelefonnay svyaz v grajdanskoy aviatsii.

Coyne, W. (2014). A review and history of the air traffic-collegiate training initiative program. International Journal of Aviation, Aeronautics, and Aerospace, 1(3). Retrieved from https://commons.erau.edu/ijaaa/ vol1/iss $3 / 4$

Coyne, W., Rice, S. C., Winter, S., Tamilselvan, G., \& Drechsel, P. V. (2017). Simulation challenges - student perception of air traffic control simulation. International Journal of Aviation, Aeronautics, and Aerospace, 4(3). https://doi.org/10.15394/ijaaa.2017.1088

Faulconer, E. K., Wood, B., \& Griffith, J. C. (2020). Infusing humanities in STEM education: Student opinions of disciplinary connections in an introductory chemistry course. Journal of Science Education and Technology, 29. https://doi.org/10.1007/s10956-020-09819-7

Fussell, S. G., \& Truong, D. (2020). Preliminary results of a study investigating aviation student's intentions to use virtual reality for flight training. International Journal of Aviation, Aeronautics, and Aerospace, 7(3). Retrieved from https://commons.erau.edu/ ijaaa/vol7/iss $3 / 2$

Gorbachev, O., Shestakov, V., \& Stefański, K. (2019). Assessment of professionally important qualities aviation technical staff. AIP Conference Proceedings 2077, 020022. https://doi.org/10.1063/1.5091883

Grudzinskiy, A. O. (2017). Razrabotka obrazovatelnix programm v usloviyax povisheniya konkurentosposobnosti ekonomicheskogo obrazovaniya: sbornik tezisov dokladov i statey Metodicheskoy konferentsii NNGU im. N.I. Lobachevskogo 6-8 fevralya 2017 goda / Nijniy Novgorod: izd-vo NNGU, 193 s.http://www.iee.unn.ru/wp-content/uploads/ sites/9/2017/11/Sbornik-statej-metodicheskoj-konferentsii-2017IEP.pdf 
International Civil Aviation Organization. (2006). Doc 7300/9 ICAO. convention on international civil aviation. Изд. https://www.icao.int/publications/Documents/7300_9ed.pdf

International Civil Aviation Organization. (2009). Cir 323 AN/185 ICAO. Guidelines for aviation English training programmes. https://skybrary.aero/bookshelf/books/2500.pdf International Civil Aviation Organization. (2011). Doc 7192-AN/857, ICAO. training manual. Part D-3. Flight operations officer/dispatcher. https://www.academia.edu/39122311/Doc_7192_AN_857_Part_D_3_t raining_manual

Kazak, V. M., Prokhorenko, I. V., \& Tymoshenko, N. A. (2017). Impact of training process of aviation specialists on flight safety parameters, Electronics and Control Systems, 2(52), 50-55. doi:10.18372/19905548.52. 11869

McGunagle, D., \& Zizka, L. (2020). Employability skills for 21st century STEM students: The employers' perspective. Higher Education, Skills and Work-Based Learning. https://doi.org/10.1108/ HESWBL-102019-0148

Publications Office of the EU. (2015). Commission Regulation (EU) 2015/340 of 20 February 2015 laying down technical requirements and administrative procedures relating to air traffic controllers' licences and certificates pursuant to Regulation (EC) No 216/2008 of the European Parliament and of the Council, amending Commission Implementing Regulation (EU) No 923/2012 and repealing Commission Regulation (EU) No 805/2011. https://op.europa.eu/en/publication-detail/-/publication/2d88da09-c3ce11e4-bbe1-01 aa75ed71a1/language-en/format-PDF/source-181146728

Stabback, P. (2016). What makes a quality curriculum? Progress Reflection No. 2 on "Current and Critical Issues in Curriculum and Learning". UNESCO International Bureau of Education. https://unesdoc.unesco.org/ark:/48223/pf0000243975

Vozdushnyj Kodeks Respubliki Uzbekistan. (1993). Air code of The Republic of Uzbekistan. https://lex.uz/docs/55599

Watkins, D., Newcomer, J. M., Earnhardt, M. P., Marion, J. W., Opengart, R. A., \& Glassman, A. M. (2016). A cross-sectional investigation of the relationships education, certification, and experience have with knowledge, skills, and abilities among aviation professionals. International Journal of Aviation, Aeronautics, and Aerospace, 3(1). https://doi.org/10.15394/ijaaa.2016.1101 